\title{
Knowledge and Perception Regarding Hypertension among Hypertensive Patients at a Tertiary Hospital in Kathmandu, Nepal
}

\section{Sabita Pandey Bashyal ${ }^{1}$ and Narbada Thapa ${ }^{2}$}

${ }^{1} \mathrm{PhD}$ Scholar, Mewar University, Rajasthan, India

${ }^{2}$ Professor, Tribhuvan University, Kirtipur, Nepal

\section{Corresponding Author}

Sabita Pandey Bashyal

Email: meetsp4@gmail.com

\section{ABSTRACT}

Background: Hypertension has a great impact on cardiovascular disease and death all over the world. Low and middle-income countries including Nepal are facing higher disease burden because of complications arise from uncontrolled hypertension. Patient's knowledge and perception play an important role for the proper management of hypertension. There are limited studies related to knowledge and perception of hypertension, therefore, this study aimed to assess the knowledge and perception of hypertension among hypertensive patients at a tertiary hospital in Nepal.

Methods: This is a hospital based, mixed-method, cross-sectional study which was conducted among 400 hypertensive patients in the outpatient department of Sahid Gangalal National Heart Center, Kathmandu, Nepal. Patients who were diagnosed as hypertensive at least 6 months before were selected by simple random sampling technique and were interviewed using semistructured questionnaire, and interview schedule from March to May 2019. Data were analyzed using descriptive and inferential statistics.

Results: The mean age of the respondents was $58.86 \pm 11.07$ years and nearly half $(47.8 \%)$ of them were in the age group of 60 years and above. More than half, (58\%) were male, $77.8 \%$ were overweight, about half of them had a significant family history of hypertension with first degree relatives. Regarding the knowledge, the total mean score was $16.16 \pm 3.032$ and had significant difference with age $(p=0.002)$, gender $(p=.000)$, education $(p=0.002)$, occupation $(\mathrm{p}=0.000)$, and duration of HTN diagnosis $(\mathrm{p}=0.000)$. Majority of them perceived hypertension as less serious illness and had significant difference with education level $(p=0.001)$ and duration of HTN diagnosis $(p=0.000)$.

Conclusions: Majority of participants had inadequate knowledge of hypertension and they perceived hypertension as less severe illness which might hinder the adherence to treatment recommendations. Hence, mass awareness program strategies might be helpful to increase hypertension related knowledge and perception.

\section{KEYWORDS}

Hypertension, Knowledge, Perception, Tertiary hospital 


\section{INTRODUCTION}

Hypertension is becoming a major public health burden globally, because of its higher morbidity, mortality, disability and financial burden mainly among adults who have a productive life. It is the main and very important modifiable risk issue for cardiovascular problems, stroke, renal problems, and retinopathy(Weber et al., 2014). Early detection and adequate prevention strategies with proper treatment, and control must pay high attention to reduce the disease burden (Miller, Berra, \& Long, 2010). Hypertension is the most known significant risk factor causing untimely death due to cardiovascular and cerebrovascular problems.

According to World Health organization (WHO), more than $80 \%$ of deaths from HTN and related cardiovascular diseases (CVDs) currently arise in low and middle-income countries and is predominantly common among persons of low socio-economic status(World Health Organization, 2013).The presence of hypertension more than doubles the risk for coronary heart disease; including acute myocardial infarction and sudden death and more than triples the risk of congestive heart failure and strokes. Obesity, unhealthy diet, diabetes mellitus, excessive alcohol intake, physical inactivity and smoking are considered as risk factors for hypertension(World Health Organization, 2013).

The trends of hypertension (HTN) are increasing every year because of the changing pattern of lifestyle behaviors in Nepal (Koju et al., 2015), and the prevalence of HTN is reported to be increasing rapidly in the urban areas and the same trend is in rural areas too (Vaidya, Aryal, \& Krettek, 2013). Lack of knowledge about the morbidity, complications and the method of control and management of hypertension contributes to a large percentage of undetected and untreated hypertensive peoples in the community (Vaidya, Oli, Eiben, \& Krettek, 2017).

Several former studies identified that there was a significant lack of awareness about the reasons of hypertension and its complications among the hypertensive patients(Sofia et al. 2018, Kongarasan and Shah 2018, Iyalomhe and Iyalomhe 2010) . A hospital based study conducted in Kathmandu found the respondents' knowledge regarding hypertension was poor (Acharya \& Chalise, 2011). Another study had revealed that adequate knowledge of hypertension is related with better control of hypertension (Sharma, Bhuvan, Alrasheedy, Kaundinnyayana, \& Khanal, 2014). However, community based studies have shown inadequate knowledge, poor attitude and practice among patients with hypertension in Nepal (Shrestha et al. 2016)and Pakistan (Almas et al. 2012).Such level of knowledge, attitude and practice affect the control of high blood pressure despite of appropriate treatment. Likewise, a study in peri-urban area of Nepal with cardiovascular diseases suggests that the community awareness of such diseases is poor (Vaidya, Pathak, \& Pandey, 2012). Therefore, health care professionals must not only diagnose and treat patients with hypertension but also create awareness about prevention and management strategies to decrease the prevalence and complications of HTN. Hence, the researcher was interested to assess the knowledge and perception of hypertension among hypertensive patients. 


\section{METHODS}

A hospital-based mixed method, cross-sectional study was conducted among hypertensive patients who were in follow up visit at the outpatient department (OPD) of Sahid Gangalal National Heart Center (SGNHC), Kathmandu, Nepal. The inclusion criteria were age above 20 years, diagnosed hypertension before six months, attended counseling session, on follow up visit, can communicate in the Nepali language, and not seriously ill. A simple random sampling technique was used to select the desired sample on the ratio of 5-6 participants every day and was interviewed using a semi-structured questionnaire after taking informed written consent. Hypertension Knowledge Level Scale (HKLS), contained 24 HTN knowledge related questions was used to assess knowledge on risk factors, management and complications of HTN. Each correct answer was scored as 1 and incorrect as 0 . The HTN perception was assessed using the Brief Illness Perception Questionnaire (BIPQ) which contained two parts. First part had eight perception related statements in 10 point Likert type scale which was scored 0 as not at all and 10 as very severe. A higher score indicates the more severe perception and a lower score indicates less severe perception. The total score was categorized as less severe (<median score) and more severe ( $>$ median score). The total possible HTN perception score was 80 . In-depth interview was carried out with 32 participants concurrently for qualitative data. Data collection was carried out from March to May 2019. Collected data were analyzed using descriptive and inferential statistics using Statistical Package for the Social Sciences (SPSS). Ethical approval was taken from the institutional review committee of SGNHC for the study.

\section{RESULTS}

From the 400 participants, the mean age was $58.75 \pm 11.14$, majority, (58.3\%) were males, $41.7 \%$ were from Brahmin/Chetri ethnic group, higher percentage, $(55.8 \%)$ received at least secondary level education, 99.5\% were married, living with family in urban setting $(68.8 \%)$ and $80.2 \%$ followed Hinduism. The majority, (78\%) were overweight, 38.5\% were homemakers, $40.3 \%$ had average monthly family income 21-40 and 41-60 thousand Nepalese Rupees respectively. Nearly half of them (49.5\%) had a significant family history of HTN in first degree relatives, and $43.25 \%$ had 5-10 years duration of HTN diagnosis.

The HTN knowledge mean score was $16.16 \pm 3.032$ (total 24) among the participants. The higher knowledge mean score was found among age $>60$ years, male, Brahmin/Chetri, higher education level, service by occupation, residing in urban areas, no family history of HTN and having HTN for $>10$ years. There was statistically significant difference on HTN knowledge with most of the socio-demographic variables like age $(p=0.002)$, gender $(p=0.000)$, ethnicity $(\mathrm{p}=0.002)$, religion $(\mathrm{p}=0.000)$, education level $(\mathrm{p}=0.002)$, occupation $(\mathrm{p}=0.001)$, residence $(\mathrm{p}=0.000)$ and duration of HTN diagnosis $(0.000)$ (Table 1 and 2$)$.

Regarding the perception, the median score was 40ranged from 30-48. Fifty eight percent of the participants perceived HTN as a less serious illness and $42 \%$ perceived as a more serious illness. Regarding the individual dimension of perception, the dimension of timeline and 
treatment control had the highest median score, (8) which indicates hypertensive patients had perceived HTN will remain for long time or even for life long and treatment can control the disease but not cure. The dimension of disease concern and understanding had a medium level score (6) which indicates hypertensive patient's understanding about HTN and concern about their illness is in medium level. Likewise, identity or symptom experience and emotional effects had a very low (2) median score which indicates most of the hypertensive patients did not experience very much physical symptoms from HTN and they were not emotional as well about their HTN and takes easily. They perceived HTN very lightly because of not experiencing physical and emotional problems (Table 3).

The causal dimension of HTN was assessed by asking to list out the three most important causes of HTN in their opinion and were found unhealthy diet $(90.5 \%)$, overweight $(85.2 \%)$ and inactivity $(79.5 \%)$ respectively. Because of urbanization and mechanization, peoples in urban areas eat unhealthy diets, no physical activities and getting fatty so many diseases were developed like high blood pressure. Several participants stated stress and heredity were also the causes of HTN (Table 4).

The perception of HTN dimension had significant difference with most of the sociodemographic variables. The dimension of consequences had a statistically significant difference ( $\mathrm{p}$ value $<0.05$ ) with all of the selected socio-demographic variables, BMI and HTN duration. The dimension of timeline had a significant difference with all selected seven socio-demographic variables. Likewise, the dimension of personal control had a significant difference with the occupation, address, family history and duration of HTN but not with age, gender and education. The dimension of treatment control also had a significant difference with age, gender, occupation, and duration of HTN. The identity or symptom experience dimension had a significant difference with all six socio-demographic variables except the address. Similarly, the dimension of illness concern had a significant difference with age, gender, occupation and family history. The dimension of understanding and emotions had a significant difference with all the six socio-demographic variables except gender and address respectively (Table 5).

Table 1: Relationship of HTN Knowledge with Socio-demographic Variables

$(n=400)$

\begin{tabular}{|c|c|c|c|c|c|}
\hline \multicolumn{2}{|l|}{ Variables } & \multirow{2}{*}{$\begin{array}{l}\mathbf{N}(\%) \\
18(4.5)\end{array}$} & \multicolumn{2}{|c|}{ Knowledge score } & \multirow{2}{*}{\begin{tabular}{|l} 
p value \\
$0.002 * *$
\end{tabular}} \\
\hline Age (year) & $20-39$ & & $\begin{array}{l}\text { Mean } \\
15.77\end{array}$ & $\begin{array}{l}\text { SD } \\
2.60\end{array}$ & \\
\hline & $40-59$ & $189(47.2)$ & 15.63 & 3.47 & \\
\hline & 60 and above & $193(48.3)$ & 16.70 & 2.38 & \\
\hline \multirow[t]{2}{*}{ Gender } & Male & $233(58.2)$ & 16.76 & 2.34 & $0.000 *$ \\
\hline & Female & $167(41.8)$ & 15.31 & 3.56 & \\
\hline \multirow{3}{*}{ Ethnicity } & Brahmin/Chetri & $169(42.2)$ & 16.77 & 3.41 & \\
\hline & Newar & $139(34.8)$ & 14.96 & 2.67 & $0.002 * *$ \\
\hline & Janajati & $48(12)$ & 16.72 & 1.99 & \\
\hline
\end{tabular}


ISSN: 2362-1303 (Paper) | eISSN: 2362-1311 (Online)

JOURNAL OF ADVANCED ACADEMIC RESEARCH (JAAR)

June 2020

\begin{tabular}{|c|c|c|c|c|c|}
\hline & Others & $44(11)$ & 15.93 & 3.27 & \\
\hline \multirow[t]{2}{*}{ Religion } & Hindu & $321(80.2)$ & 12.84 & 4.61 & $0.000 *$ \\
\hline & Non Hindu & 79 (19.8) & 16.07 & 2.41 & \\
\hline \multirow{5}{*}{$\begin{array}{l}\text { Education } \\
\text { level }\end{array}$} & Illiterate & $25(6.2)$ & 15.74 & 2.81 & \\
\hline & $1-5$ class & 76 (19) & 15.38 & 2.62 & $0.002 * *$ \\
\hline & 6-10 class & $116(29)$ & 16.25 & 2.69 & \\
\hline & $11-12$ class & $107(26.8)$ & 17.28 & 3.23 & \\
\hline & $12+$ & $76(19)$ & 16.89 & 2.40 & \\
\hline \multirow[t]{4}{*}{ Occupation } & Service & $91(22.8)$ & 16.94 & 3.26 & $0.001 * *$ \\
\hline & Business & $51(12.8)$ & 16.36 & 2.70 & \\
\hline & Agriculture & $104(26)$ & 14.86 & 3.69 & \\
\hline & Homemaker & $154(38.5)$ & 16.64 & 2.34 & \\
\hline \multirow[t]{2}{*}{ Address } & Urban & $274(68.5)$ & 18.20 & 1.93 & $0.000 *$ \\
\hline & Rural & $126(31.5)$ & 16.84 & 1.64 & \\
\hline \multirow[t]{2}{*}{ Marital status } & Married & $398(99.5)$ & 17.24 & 17.68 & $0.165^{*}$ \\
\hline & Unmarried & $2(0.5)$ & 15.77 & 2.60 & \\
\hline \multirow{4}{*}{$\begin{array}{l}\text { Monthly } \\
\text { family } \\
\text { Income (NRS } \\
\text { in thousands) }\end{array}$} & $10-20$ & $29(7.2)$ & 15.63 & 3.47 & \\
\hline & $21-40$ & $161(40.2)$ & 16.70 & 2.38 & $0.184 * *$ \\
\hline & $41-60$ & $161(40.2)$ & 16.76 & 2.34 & \\
\hline & $>60$ & $49(12.2)$ & 15.31 & 3.56 & \\
\hline
\end{tabular}

** ANOVA, * independent sample t-test, bold- significant values, significant level $\leq 0.05$, CI 95\%

Table 2: Relationship of HTN Knowledge with BMI and HTN Related Variables (n=400)

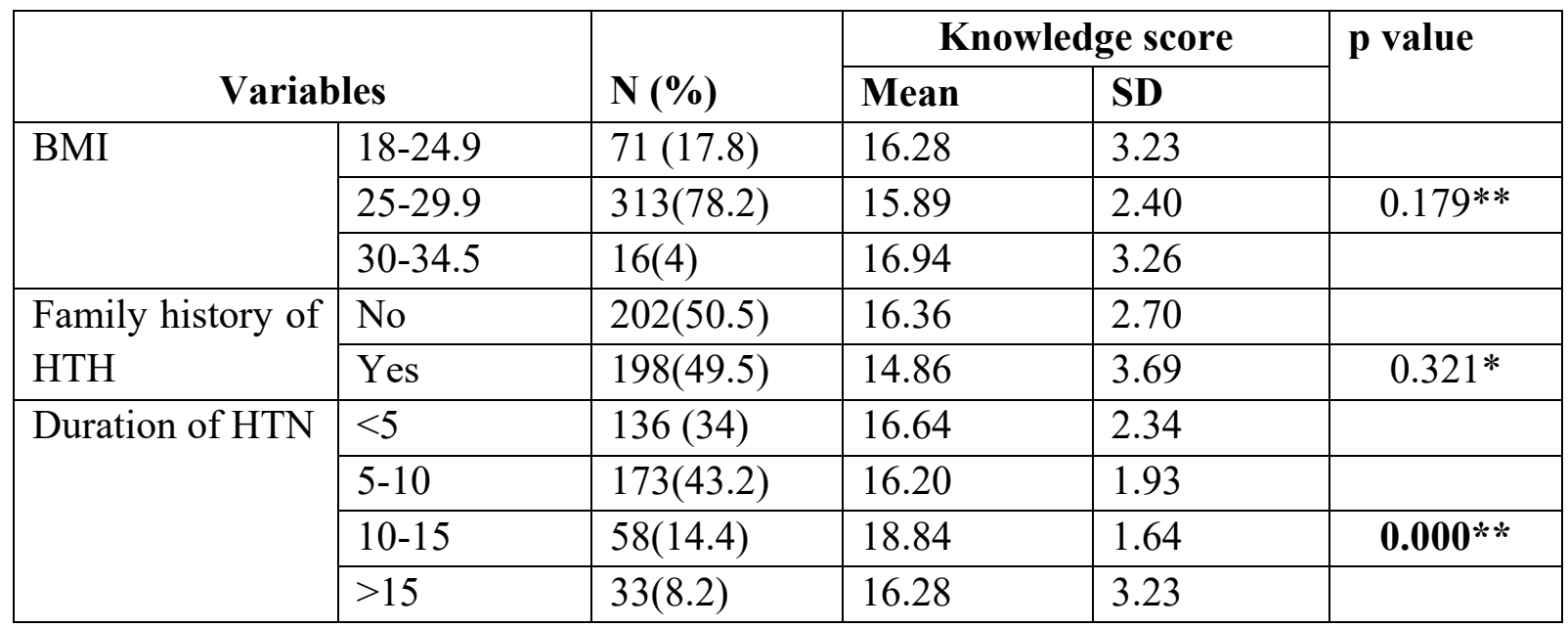

** ANOVA, * independent sample t-test, bold- significant values, significant level $\leq 0.05$, CI 95\% 
ISSN: 2362-1303 (Paper) | eISSN: 2362-1311 (Online)

JOURNAL OF ADVANCED ACADEMIC RESEARCH (JAAR)

Table 3: Perception of HTN

$\mathrm{n}=\mathbf{4 0 0}$

\begin{tabular}{|l|l|c|l|l|l|}
\hline \multirow{2}{*}{ Dimensions } & Median & \multirow{2}{*}{\begin{tabular}{l}
\multirow{2}{*}{ MQR } \\
\cline { 4 - 6 }
\end{tabular}} & \multicolumn{3}{|c|}{ Level of perception } \\
\cline { 4 - 6 } & & 4 & $232(58)$ & $168(42)$ & Low \\
\hline Total perception (80) & $40(30-48)$ & 1 & $251(62.8)$ & $149(37.2)$ & Low \\
\hline Consequences & $4(3-60)$ & 2 & $133(58.2)$ & $167(41.8)$ & High \\
\hline Timeline & $8(1-10)$ & 1 & $221(55.2)$ & $179(44.8)$ & Low \\
\hline Personal control & $3(0-5)$ & 1 & $250(62.5)$ & $150(37.5)$ & High \\
\hline Treatment control & $8(2-9)$ & 1 & $256(64.0)$ & $144(36.0)$ & Low \\
\hline Identity & $2(1-4)$ & 2 & $323(80.8)$ & $77(19.5)$ & Low \\
\hline Concern & $6(5-8)$ & 1 & $323(80.8)$ & $77(19.2)$ & Low \\
\hline Understanding & $6(5-8)$ & 3 & $201(50.2)$ & $199(49.8)$ & Low \\
\hline Emotions & $2(0-5)$ & & & & \\
\hline
\end{tabular}

IQR- interquartile range, perception score $<7.5$ (75\%) low level and score $>7.5$ (75\%) high level of perception.

Table 4: Perceived Causes of HTN (Multiple Responses) $\quad \mathbf{n}=\mathbf{4 0 0}$

\begin{tabular}{|l|l|l|l|}
\hline \multirow{2}{*}{ Perceived causes } & \multicolumn{2}{|c|}{ Responses } & \multirow{2}{*}{$\%$ of cases } \\
\cline { 2 - 3 } & $\mathbf{N}$ & 24.1 & \\
\hline Unhealthy diet & 238 & 22.7 & $90.5 \%$ \\
\hline Over weight & 224 & 21.2 & $85.2 \%$ \\
\hline Inactivity & 209 & 18.0 & $79.5 \%$ \\
\hline Stress & 177 & 14.0 & $67.3 \%$ \\
\hline Heredity & 138 & 100 & $52.5 \%$ \\
\hline Total & 986 & $374.9 \%$ \\
\hline
\end{tabular}

Table 5: Relationship of Illness Perception with Socio-demographic Variables

$\mathrm{n}=\mathbf{4 0 0}$

\begin{tabular}{|l|l|l|l|l|l|l|l|l|}
\hline \multirow{2}{*}{ Variables } & \multicolumn{7}{|c|}{ Dimensions of HTN perception } \\
\cline { 2 - 9 } & $\begin{array}{l}\text { Consequence } \\
\text { s }\end{array}$ & Timeline & $\begin{array}{l}\text { Personal } \\
\text { control }\end{array}$ & $\begin{array}{l}\text { Treatment } \\
\text { control }\end{array}$ & Identity & Concern & Understanding & Emotions \\
\hline Age & $\mathbf{0 . 0 0 0}$ & $\mathbf{0 . 0 0 0}$ & 0.410 & $\mathbf{0 . 0 7 0}$ & $\mathbf{0 . 0 0 0}$ & $\mathbf{0 . 0 0 0}$ & $\mathbf{0 . 0 2 4}$ & $\mathbf{0 . 0 0 1}$ \\
\hline Gender & $\mathbf{0 . 0 0 0}$ & $\mathbf{0 . 0 0 0}$ & 0.464 & $\mathbf{0 . 0 0 0}$ & $\mathbf{0 . 0 0 0}$ & $\mathbf{0 . 0 0 3}$ & 0.082 & $\mathbf{0 . 0 0 0}$ \\
\hline Education & $\mathbf{0 . 0 0 0}$ & $\mathbf{0 . 0 0 0}$ & 0.255 & 0.108 & $\mathbf{0 . 0 0 0}$ & 0.450 & $\mathbf{0 . 0 0 0}$ & $\mathbf{0 . 0 0 0}$ \\
\hline Occupation & $\mathbf{0 . 0 0 9}$ & $\mathbf{0 . 0 0 0}$ & $\mathbf{0 . 0 1 8}$ & $\mathbf{0 . 0 0 0}$ & $\mathbf{0 . 0 0 0}$ & $\mathbf{0 . 0 0 0}$ & $\mathbf{0 . 0 0 0}$ & $\mathbf{0 . 0 0 1}$ \\
\hline Address & $\mathbf{0 . 0 0 0}$ & $\mathbf{0 . 0 0 0}$ & $\mathbf{0 . 0 0 0}$ & 0.392 & 0.175 & 0.139 & $\mathbf{0 . 0 0 1}$ & 0.235 \\
\hline
\end{tabular}


ISSN: 2362-1303 (Paper) | eISSN: 2362-1311 (Online)

JOURNAL OF ADVANCED ACADEMIC RESEARCH (JAAR)

June 2020

\begin{tabular}{|l|l|l|l|l|l|l|l|l|}
\hline $\begin{array}{l}\text { Family } \\
\text { history }\end{array}$ & 0.129 & $\mathbf{0 . 0 4 3}$ & $\mathbf{0 . 0 0 7}$ & 0.213 & $\mathbf{0 . 0 2 0}$ & $\mathbf{0 . 0 2 2}$ & $\mathbf{0 . 0 0 4}$ & $\mathbf{0 . 0 0 1}$ \\
\hline $\begin{array}{l}\text { Duration of } \\
\text { HTN }\end{array}$ & $\mathbf{0 . 0 0 0}$ & $\mathbf{0 . 0 0 0}$ & $\mathbf{0 . 0 2 4}$ & $\mathbf{0 . 0 0 0}$ & $\mathbf{0 . 0 0 3}$ & 0.200 & $\mathbf{0 . 0 0 0}$ & $\mathbf{0 . 0 0 0}$ \\
\hline
\end{tabular}

p values from Kruskal-Wallis test, bold-significant values, significant level $\leq 0.05$, CI 95\%

\section{DISCUSSION}

Four hundred diagnosed cases of hyper-tension were selected from the Cardiology OPD of a tertiary hospital to assess knowledge and perception of HTN among hypertensive patients. The mean age of the participants was $58.75 \pm 11.14$ years with the highest proportion $(48.3 \%)$ at the age group of $>60$ years followed by $40-59$ years (47.2\%). It might be because the age $>40$ years is considered as an important risk factor for HTN (Chobanian et al., 2003). The result of this study was in line with the results of a study conducted in Nepal (Acharya \& Chalise, 2011) which stated that the mean age was 51.26 years among hypertensive patients. Likewise, a study conducted in Malaysia (Ramli, Ahmad, \& Paraidathathu, 2012) reported that the mean age of patients with HTN was 57.84 years.

The percentage of males was more, $(58.3 \%)$ than the females in this study which is in line with previous studies conducted in Nepal reported 57\% of hypertensive patients were males and 49.4\% were females(R. Karmacharya \& Paudel, 2018). Similarly, studies conducted in Pakistan and Taiwan also stated that $63.6 \%$ and $60.3 \%$ of the hypertensive patients were males in their studies (Kibria et al. 2018, Bilal et al. 2015). It is considered that HTN is more prevalent among males but after the age of fifty, there is also increasing the trends among females. Almost, all patients $(99.5 \%)$ were married which was similar to several previous studies (Acharya and Chalise 2011, Bilal et al. 2015). The majority of them, (80\%) were from the Hindu religion because Hinduism is a more prominent religion in Nepal. This result was also similar to other previous studies done in Nepal which reported more than $80 \%$ were Hindu by religion (Acharya and Chalise 2011, Kibria et al. 2018).

Regarding the education status, about $94 \%$ were literate and $46 \%$ of them had received high school or above education was a contrast with the study done by Maharjan which reported majority were uneducated (Maharjan, Leelacharas, \& Prapaipanich, 2018). It might be because of the variation in the study setting. The current study was done in a central hospital among hypertensive patients who were in follow up visits at the hospital, whereas, in another study the study setting was a peri-urban area. Educated people might be more aware in comparison to uneducated regarding the importance of regular follow-ups as recommended and possibly were more likely to come for follow-up visits. Regarding the occupation, the highest percentage, $(38.5 \%)$ did not have specific income-generating occupations and engaged in household works. It might be because the highest proportion of participants were from the age group of more than 60 years so they were already retired from the job or not working in the agriculture field and the 
majority of women may engage in household works. These findings were compared with the findings from previous HTN related studies (Acharya and Chalise 2011, B. M. Karmacharya et al. 2017a).

The mean BMI was $26.97 \pm 1.93 \mathrm{~kg} / \mathrm{m}^{2}$ in the current study which was in line with the study done in Nepal (B. M. Karmacharya et al., 2017a) and Iran (Bilal et al., 2015) reported the mean BMI of the hypertensive participants was $26.60 \pm 4.4$ and $27.6 \pm 1.37$ respectively. It is evident that the HTN is more prevalent among overweight people and considered a risk factor of HTN. Similarly, $78 \%$ of the participants were overweight it might be due to the majority of urban residents tend to be overweight than the rural areas. This is comparable with the study conducted by Manandhar and Koju in semi-urban areas of Nepal(Manandhar, Koju, Sinha, 2012) reported $54.4 \%$ of the hypertensive patients were overweight. Similarly, another study conducted in Nepal to assess cardiovascular risk factors also reported that $67.7 \%$ had overweight whose BMI was $\geq 25 \mathrm{~kg} / \mathrm{m}^{2}$ (Gautam et al., 2017).

Family history is a significant risk factor for HTN. As reported by Zhang, the person who has first-degree relatives with hypertension had double the risks for developing hypertension than the person without any family history of HTN(Zhang et al., 2013) . In the current study, about $50 \%$ of hypertensive patients had a significant family history of HTN was comparable with other former Nepalese studies(Maharjan, Leelacharas, and Prapaipanich 2018, Adrega et al. 2018) which stated $51.17 \%$ and $40 \%$ of the hypertensive participants had a significant family history of HTN. Similarly, a study conducted in India and China reported that $64 \%$ and $74.7 \%$ of hypertensive participants had a family history of HTN(Zhang et al. 2013, Kaur et al. 2012).In this study, the mean duration of HTN diagnosis was 7.86 years was comparable with the study that reported the mean length of time since the diagnosis of hypertension was 8.59 years and 8.25 years respectively (Pyakurel et al. 2019, Ramli, Ahmad, and Paraidathathu 2012). Similarly, in the current study, $34 \%$ had $<5$ years and $8.2 \%$ had $>15$ years duration of HTN diagnosis which is comparable with a similar study done in Turkey and Pakistan which stated that $32.4 \%$ had $<5$ years of HTN duration and about $10 \%$ of the hypertensive patients had $>15 \mathrm{yrs}$ duration of HTN diagnosis(Kibria et al., 2018).

In the current study, mean score of illness perception was $40.47 \pm 3.151$ which represented a less threatening view of hypertension perception. Previous studies on illness perception among patients with hypertension showed similar results (Norfazilah A et al. 2013, Saarti et al., 2015). However, the mean scores in the current study were slightly higher than the earlier studies which might suggest that the Nepalese patients perceived hypertension slightly more severe illness. Participants in current study did not face severe consequences in their lives because of HTN. They did not experience that much physical (2.30 \pm 0.991$)$ and emotional (2.23 \pm 1.749$)$ symptoms as the mean score in those two dimensions were very low which might be the cause of less threatening view of HTN perception.

In the other hand, the timeline and treatment control dimensions had high mean score $(8.03 \pm 1.512$ and $8.12 \pm 0.725)$ in comparison to other dimensions in this study which could be interpreted as HTN is lifelong illness but can be controlled by taking medicines therefore 
patients might be perceived HTN is less severe. The finding of this study is in line with other study which showed similar results (Newtonraj, Arun, Bazroy, \& Tovia, 2017). In current study personal control had low mean score than the treatment control which may be due to less confident to follow prescribed behavior treatment and behavior modifications than taking prescribed medications. This finding was consistent with previous studies where the patients preferred treatment control over personal control (Norfazilah A et al. 2013, Nivedita 2015, Ross, Walker, and MacLeod 2004).

In the current study, there was significant association seen between hypertension knowledge and some socio-demographic variables like age $(p=.007)$, sex $(p=.021)$, education level $(p=.000)$, duration of HTN $(p=.000)$. This result was comparable with the similar study done in Nepal which showed the duration of hypertension $(\mathrm{P}<.001)$, years of school completed $(\mathrm{P}<.01)$, and age $(\mathrm{P}<.01)$ were significantly associated with hypertension knowledge scores $(\mathrm{B}$. M. Karmacharya et al., 2017b). It is obvious that, because of education and experience person can gain more knowledge so in these study respondents who were educated and had longer duration of HTN diagnosis had more knowledge. Regarding the perception of HTN there was significant association with education level $(\mathrm{p}=0.001)$ and duration of HTN $(0.000)$ which is in line with the previous study (Nivedita, 2015) whereas in another study education and HTN duration showed no significant difference (Norfazilah et al., 2013) but family history had significant difference with perception.

\section{CONCLUSIONS}

Majority of respondents had adequate overall knowledge on hypertension but they had less knowledge on complications of hypertension. Therefore they perceived HTN as less severe illness which might hinder the recommended treatment adherence including lifestyle modification. They were perceived HTN as less threatening illness and it can be controlled by treatment. Therefore awareness strategies need to be focused on complications of uncontrolled HTN and importance of self-care behaviors.

\section{REFERENCES}

Acharya, R., \& Chalise, H. N. (2011). Life style of patient before and after diagnosis of hypertension in Kathmandu. Health, 03(08), 490-497.

https://doi.org/10.4236/health.2011.38081

Adrega, T., Ribeiro, J., Santos, L., \& Santos, J. A. (2018). Prevalence of cardiovascular disease risk factors, health behaviours and atrial fibrillation in a Nepalese post-seismic population: a cross-sectional screening during a humanitarian medical mission. Nepalese Heart Journal, 15(2), 9-14. https://doi.org/10.3126/njh.v15i2.21470

Almas, A., Godil, S. S., Lalani, S., Samani, Z. A., \& Khan, A. H. (2012). Good knowledge about hypertension is linked to better control of hypertension; A multicentre cross sectional study in Karachi, Pakistan. BMC Research Notes, 5(1), 1. https://doi.org/10.1186/1756-0500-5579 
Bilal, M., Haseeb, A., Lashkerwala, S. S., Zahid, I., Siddiq, K., Saad, M., ... Yaqub, A. (2015). Knowledge, Awareness and Self-Care Practices of Hypertension Among Cardiac Hypertensive Patients. Global Journal of Health Science, 8(2). https://doi.org/10.5539/gjhs.v8n2p9

Chobanian, A. V, Bakris, G. L., Black, H. R., Cushman, W. C., Green, L. A., Izzo, J. L., ... National High Blood Pressure Education Program Coordinating Committee. (2003). Seventh report of the Joint National Committee on Prevention, Detection, Evaluation, and Treatment of High Blood Pressure. Hypertension (Dallas, Tex. : 1979), 42(6), 1206-1252. https://doi.org/10.1161/01.HYP.0000107251.49515.c2

Gautam, M. P., Ghimire, U., Shrestha, K. M., Paudel, B., Khatiwada, P., \& Adhikari, B. (2017). Prevalence, Awareness and Control of Hypertension in a Well-Educated Professional Group in Nepal. Nepalese Heart Journal, 14(1), 21. https://doi.org/10.3126/njh.v14i1.17191

Iyalomhe, G. B. S., \& Iyalomhe, S. I. (2010). Hypertension-related knowledge, attitudes and lifestyle practices among hypertensive patients in a sub-urban Nigerian community. Journal of Public Health and Epidemiology, 2(4), 71-77. Retrieved from http://www.academicjournals.org/jphe

Karmacharya, B. M., Koju, R. P., LoGerfo, J. P., Chan, K. C. G., Mokdad, A. H., Shrestha, A., ... Fitzpatrick, A. L. (2017a). Awareness, treatment and control of hypertension in Nepal: Findings from the Dhulikhel Heart Study. Heart Asia, 9(1), 1-8. https://doi.org/10.1136/heartasia-2016-010766

Karmacharya, B. M., Koju, R. P., LoGerfo, J. P., Chan, K. C. G., Mokdad, A. H., Shrestha, A., ... Fitzpatrick, A. L. (2017b). Awareness, treatment and control of hypertension in Nepal: Findings from the Dhulikhel Heart Study. Heart Asia, 9(1), 1-8. https://doi.org/10.1136/heartasia-2016-010766

Karmacharya, R., \& Paudel, K. (2018). Awareness on Hypertension and its Self-Management Practices among Hypertensive Patients in Pokhara, western Nepal. Janapriya Journal of Interdisciplinary Studies, 6, 110-120. https://doi.org/10.3126/jjis.v6i0.19313

Kaur, P., Rao, S. R., Radhakrishnan, E., Rajasekar, D., \& Gupte, M. D. (2012). Prevalence, awareness, treatment, control and risk factors for hypertension in a rural population in South India. International Journal of Public Health, 57(1), 87-94. https://doi.org/10.1007/s00038011-0303-3

Kibria, G. M. Al, Swasey, K., Kc, A., Mirbolouk, M., Sakib, M. N., Sharmeen, A., ... Stafford, K. A. (2018). Estimated Change in Prevalence of Hypertension in Nepal Following Application of the 2017 ACC/AHA Guideline. JAMA Network Open, 1(3), e180606. https://doi.org/10.1001/jamanetworkopen.2018.0606

Koju, R., Manandhar, K., Risal, A., Steiner, T. J., Holen, A., \& Linde, M. (2015). Undertreated hypertension and its implications for public health in Nepal: Nationwide population-based survey. Kathmandu University Medical Journal, 13(49), 3-7. https://doi.org/10.3126/kumj.v13i1.13744

Kongarasan, P., \& Shah, P. B. (2018). Knowledge and perception of hypertension among 
hypertensive patients attending rural health and training centre, department of community medicine, SRMC \& RI. International Journal Of Community Medicine And Public Health, 5(6), 2323. https://doi.org/10.18203/2394-6040.ijcmph20182151

Maharjan, R., Leelacharas, S., \& Prapaipanich, W. (2018). Illness Perception, Personal Characteristics, Social Support, and Lifestyle Behavior in Patients With Hypertension, Attending a Cardiac Out-Patient Department, Nepal, 41(4), 37-47.

Manandhar K., Koju R., Sinha N.P., Hu. S. (2012). Prevalence and Associated Risk Factors of Hypertension Among People Aged 50 years and more in Banepa Municipality, Nepal. $K U M J, 10(39)$. Retrieved from http://m.kumj.com.np/issue/39/35-38.pdf

Miller, N. H., Berra, K., \& Long, J. (2010). Hypertension 2008 - awareness, understanding, and treatment of previously diagnosed hypertension in baby boomers and seniors: A survey conducted by harris interactive on behalf of the preventive cardiovascular nurses association. Journal of Clinical Hypertension, 12(5), 328-334. https://doi.org/10.1111/j.1751-7176.2010.00267.x

Newtonraj, A., Arun, S., Bazroy, J., \& Tovia, S. (2017). Lay perspectives on causes and complications of hypertension; and barrier to access health care by known hypertensive patients : a qualitative study from a rural area of South India, 4(3), 704-707.

Nivedita, S. (2015). Illness Perception and Coping among Hypertension Patients. Research Journal of Recent Sciences, 4(ISC-2014), 270-273.

Norfazilah A, Samuel A, Law PT, Ainaa A, Nurul A, Syahnaz MH, \& Azmawati MN. (2013). Illness perception among hypertensive patients in primary care centre UKMMC. Malaysian Family Physician, 8(3), 19-25.

Pyakurel, P., Yadav, D. K., Thapa, J., Thakur, N., Sharma, P., Yadav, S. K., ... Jha, N. (2019). Prevalence and associated risk factor of hypertension among individuals of age 18-59 years in South-eastern Nepal: A cross-sectional study, 16(1), 19-26.

Ramli, A., Ahmad, N. S., \& Paraidathathu, T. (2012). Medication adherence among hypertensive patients of primary health clinics in Malaysia. Patient Preference and Adherence, 6, 613622. https://doi.org/10.2147/PPA.S34704

Ross, S., Walker, A., \& MacLeod, M. J. (2004). Patient compliance in hypertension: Role of illness perceptions and treatment beliefs. Journal of Human Hypertension, 18(9), 607-613. https://doi.org/10.1038/sj.jhh.1001721

Sharma, S., Bhuvan, K. C., Alrasheedy, A. A., Kaundinnyayana, A., \& Khanal, A. (2014). Impact of community pharmacy-based educational intervention on patients with hypertension in Western Nepal. Australasian Medical Journal, 7(7), 304-313. https://doi.org/10.4066/AMJ.2014.2133

Shrestha, S., Adhikari, B., Poudel, R. S., Thapaliya, K., Kharal, T., Bastakoti, M., \& Bhatta, N. K. (2016). Knowledge, attitude and practice on hypertension among antihypertensive medication users. Journal of the Nepal Medical Association, 55(204), 86-92. https://doi.org/10.31729/jnma.2848

Sofia, N., Hajra, S., Muhammad, A., \& Syed, A. G. (2018). Knowledge Attitude and Practice 
ISSN: 2362-1303 (Paper) | eISSN: 2362-1311 (Online)

JOURNAL OF ADVANCED ACADEMIC RESEARCH (JAAR)

June 2020

towards Hypertension among Adult Population in a Rural Area of Lahore, Pakistan Article (PDF Available) '. International Journal of Scientific \& Engineering Research, 9(5), 1674. Retrieved from https://www.researchgate.net/publication/327337841_Knowledge_Attitude_and_Practice_t owards_Hypertension_among_Adult_Population_in_a_Rural_Area_of_Lahore_Pakistan

Vaidya, A., Aryal, U. R., \& Krettek, A. (2013). Cardiovascular health knowledge, attitude and practice/behaviour in an urbanising community of Nepal: A population-based crosssectional study from Jhaukhel-Duwakot Health Demographic Surveillance Site. BMJ Open, 3(10), 1-11. https://doi.org/10.1136/bmjopen-2013-002976

Vaidya, A., Oli, N., Eiben, G., \& Krettek, A. (2017). The heart-health associated research, dissemination and intervention in the community (HARDIC) trial for nepalese mothers regarding diet and physical activity: A process evaluation. Kathmandu University Medical Journal, 15(58), 107-116.

Vaidya, A., Pathak, R. P., \& Pandey, M. R. (2012). Prevalence of hypertension in Nepalese community triples in 25 years: A repeat cross-sectional study in rural Kathmandu. Indian Heart Journal, 64(2), 128-131. https://doi.org/10.1016/S0019-4832(12)60045-5

Weber, M. A., Schiffrin, E. L., White, W. B., Mann, S., Lindholm, L. H., Kenerson, J. G., ... Harrap, S. B. (2014). Clinical Practice Guidelines for the Management of Hypertension in the Community: A Statement by the American Society of Hypertension and the International Society of Hypertension Clinical Practice Guidelines for the Management of Hypertension in the Comm. Journal of Clinical Hypertension, 16(1), 14-26. https://doi.org/10.1111/jch.12237

World Health Organization. (2013). A Global brief oh hypertension, 9.

Zhang, J., Huang, Q., Yu, M., Cha, X., Li, J., Yuan, Y., ... Zhong, H. (2013). Prevalence, Awareness, Medication, Control, and Risk Factors Associated with Hypertension in Bai Ethnic Group in Rural China: The Yunnan Minority Eye Study. PLoS ONE, 8(8), 1-9. https://doi.org/10.1371/journal.pone.0070886 